\title{
Pulmonary function in young females of Kolkata, India - Revisited
}

\author{
A Bandyopadhyay, R Dalui, S Pal, I Bhattacharjee, B Goswami, AS Roy \\ Sports and Exercise Physiology Laboratory, Department of Physiology, University of Calcutta, \\ University College of Science and Technology, Kolkata, India
}

Received: June 1, 2015

Accepted: March 11, 2016

\begin{abstract}
Rapid economic and industrial growths imposed significant impact on human health including the pulmonary health. Questions were raised regarding the validity of the existing prediction norms of pulmonary function tests (PFTs) in a particular population. The present study was conducted to investigate the applicability of the existing norms for PFTs in young healthy non-smoking female university students of Kolkata, India. Significant difference was noted in vital capacity (VC), forced vital capacity (FVC), and forced expiratory volume in $1 \mathrm{~s}\left(\mathrm{FEV}_{1}\right)$ when the present data were compared with the earlier study in similar population. Correlation statistic revealed significant relationship of age and body height with all the PFT parameters. Body mass had significant correlation with VC, FVC, FEV 1 as a percentage of FVC $\left(\mathrm{FEV}_{1 \%}\right)$, and peak expiratory flow rate (PEFR). Regression equations have been computed for predicting PFTs from age and body height. There has been a change of PFTs in the studied population for the last couple of decades due to increased environmental pollution in the course of economical and industrial developments. Regression equations computed in this study are not only recommended to predict PFT parameters in the studied population, but they are also considered more reliable owing to their substantially smaller standard error of estimate than those proposed in the previous study.
\end{abstract}

Keywords: $\mathrm{FVC}, \mathrm{FEV}_{1}, \mathrm{FEV}_{1 \%}, \mathrm{PEFR}$, Indian

\section{Introduction}

Pulmonary function tests (PFTs) are the fundamental tools for the evaluation of an individual's respiratory system and are also the prime clinical aids to diagnose, treat, and rehabilitate the respiratory malfunctions (2). These spirometric tests have been found to reflect the operational disorder as well as the severity of airway impedance. There are reports available on the normal pulmonary function measurements and the effects of ethnicity, anthropometric variables, and habitat on those parameters for different populations including European (5, 12, 38, 41, 43), North American (9, 14, 30), Indian (3, 4, 7, 8, 11, 27, 32, 33, 39, 42, 49), Chinese (10, 13, 50), Malaysian $(2,36,37,46,47)$, and other non-Caucasian $(16,28)$ populations.

Diet, obesity, air pollution, and physical activity are among the several major factors that significantly affect PFTs (29). As a result of rapid global economic growth and a wide range of industrialization in the last two decades, a general betterment of nutritional status of common people has occurred. On the contrary, the regular physical activity levels of common people have been reduced, and their exposure to air pollution has also been enormously increased. Under these circumstances, it is indispensable to revisit the existing population

Corresponding author: Dr. Amit Bandyopadhyay, MSc, PhD, FICN

Sports and Exercise Physiology Laboratory, Department of Physiology, University of Calcutta, University College of Science and Technology, 92 A.P.C. Road, Kolkata 700009, India

Phone: +91 3323508386 ext. 317; Fax: +91 33 23519755; E-mail: bamit74@yahoo.co.in 
specific norms of pulmonary function measurements in the light of changes in socioeconomic status, environmental consequences, and lifestyle modification that give grounds for PFTs even within the population having similar ethnicity and habitat (29). Enhancement of body height and body mass index in the last five decades caused significant changes in the anthropometric profile of young adults. Hence, the applicability of the existing population specific norms that have been proposed decades back for predicting PFTs has become questionable under the present consequences (34).

Chatterjee and Saha (8) reported the pulmonary function profile of healthy, nonsmoking women (age: 20-59 years) of Kolkata, India, 27 years back. Therefore, there is a need to re-investigate the relevance of the norms proposed in this study. In the above context, present investigation was aimed to:

a. Evaluation of pulmonary function parameters of normal young healthy non-smoking female university students in Kolkata, India.

b. Comparison of the lung function measurements with previously reported data from similar and other national as well as international counterparts.

c. Derivation of prediction equations for assuming the lung volumes of the presently studied population and comparison of these equations with the earlier norms reported by Chatterjee and Saha (8).

\section{Materials and Methods}

\section{Selection of subjects}

About 90 female university non-smoking students of 19-24 years of age with similar socioeconomic background were randomly sampled from the post-graduate section of the University of Calcutta, Kolkata, India, to conduct this cross-sectional study. Dupont and Plummer's method (17) of sample size calculation was adopted in the study setting the confidence interval at $95 \%$. Although the computed sample size for this study was 68 , the current study was conducted with 90 subjects. To limit the inter-individual differences due to age and time of year, data collection procedure was limited over a restricted time frame following the standard proposal (29). Written informed consent to participate in the study was obtained from the subjects and they filled up a questionnaire (19) to record their health status and personal demographic data. Subjects with medication or history of athletic training or any pulmonary or other diseases were excluded from this study. All the volunteers were explained and demonstrated with the detailed experimental protocol to relieve their apprehensions. Ethical clearance was obtained from the Human Ethics Committee, Department of Physiology, University of Calcutta.

\section{Preparation of subjects}

University proof was used to record the age of the subjects. The body height and body weight were measured with the subject standing barefoot and in minimum clothing with an accuracy of $\pm 0.50 \mathrm{~cm}$ and $\pm 0.1 \mathrm{~kg}$, respectively, with the help of a weight measuring instrument fitted with a height measuring rod (Avery India Ltd., India). Body surface area (BSA) was calculated using the formula of DuBois and DuBois (15).

\section{Determination of pulmonary function measurements}

Tidal volume (TV), vital capacity (VC), forced vital capacity (FVC), forced expiratory volume in $1 \mathrm{~s}\left(\mathrm{FEV}_{1}\right), \mathrm{FEV}_{1}$ as a percentage of $\mathrm{FVC}\left(\mathrm{FEV}_{1 \%}\right)$, mid-expiratory flow rate 
$\left(\mathrm{FEF}_{25-75 \%}\right)$, end expiratory flow rate $\left(\mathrm{FEF}_{75-85 \%}\right)$, and forced expiratory time were measured on a 9-L closed-circuit-type expirograph (Toshniwal Technologies Pvt. Ltd., India). Wright peak flow meter was used to record the peak expiratory flow rate (PEFR). Palmer respiratory hand pump was used to calibrate the expirograph daily. All the measurements were performed according to the standard guideline $(2,8)$. As the expiratory flow rates are highest at noon, the experiments were conducted before lunch at noon (22) and all the subjects were encouraged and motivated to attain the maximum possible effort. After a couple of practice runs, at least three satisfactory efforts were recorded for each volunteer with at least 3-5 min rest between consecutive trials as per standard norm and the highest value was accepted $(8,20)$. All pulmonary function measurements as well as the anthropometric measurements were performed in one sitting on the same day and the PFTs were expressed at body temperature and pressure saturated with water vapor.

\section{Statistical analysis}

Student's two-tailed $t$-test was adopted to compare the pulmonary function measurements and physical parameters of the subjects with the mean values of similar parameters reported by Chatterjee and Saha (8). To find the significant relationship between two parameters, Pearson's product-moment correlation coefficient $(r)$ was computed. Simple linear regression statistic was adopted for computing the prediction norms of PFTs from different physical parameters. The level of significance was set at $p<0.05$.

\section{Results}

The mean (SD) age of the subjects participated in the study was 22.06 (2.81) years. Table I represents the values of physical parameters and pulmonary function measurements as obtained in the present study as well as those reported by Chatterjee and Saha (8) in the same population. No significant difference was noted in the physical parameters between the studies. Significant differences $(p<0.001)$ were found in VC, FVC, and $\mathrm{FEV}_{1}$ from the earlier observation of Chatterjee and Saha (8), but no significant variation was noted in $\mathrm{FEV}_{1 \%}, \mathrm{FEF}_{25-75 \%}, \mathrm{FEF}_{75-85 \%}$, and PEFR between the studies.

PFTs depicted significant correlation with age, body mass, and body height (Table II). Depending on these significant correlations, prediction equations for PFTs from physical parameters were also computed (Tables III and IV).

\section{Discussion}

The pulmonary function measurements were found within the normal range in the studied population. It is difficult to compare the pulmonary function measurements of the present study with those of a foreign population due to variations in anthropometric profiles that largely affect the lung function measurements $(2,3)$. Therefore, for a valid comparison, the values of pulmonary function measurements reported in other studies were standardized with age and height according to the proposal of Bandyopadhyay et al. (3).

$\mathrm{VC}, \mathrm{FVC}$, and $\mathrm{FEV}_{1}$ were significantly $(p<0.001)$ different from those reported by Chatterjee and Saha (8), whereas the rest of the pulmonary function parameters depicted insignificant variation between the studies. Such variation in VC, FVC, and FEV 1 depicted a decrease in these parameters in university students of Kolkata over the last 20 years. 


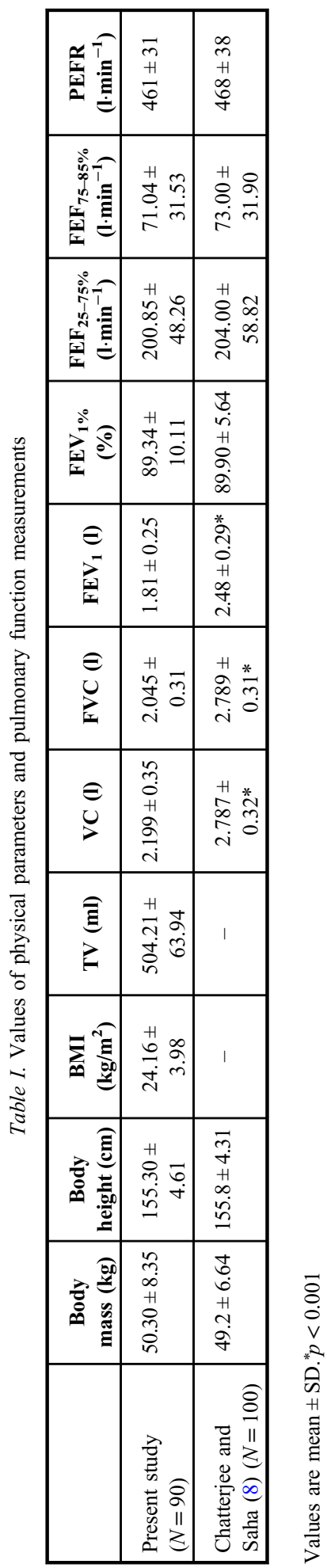

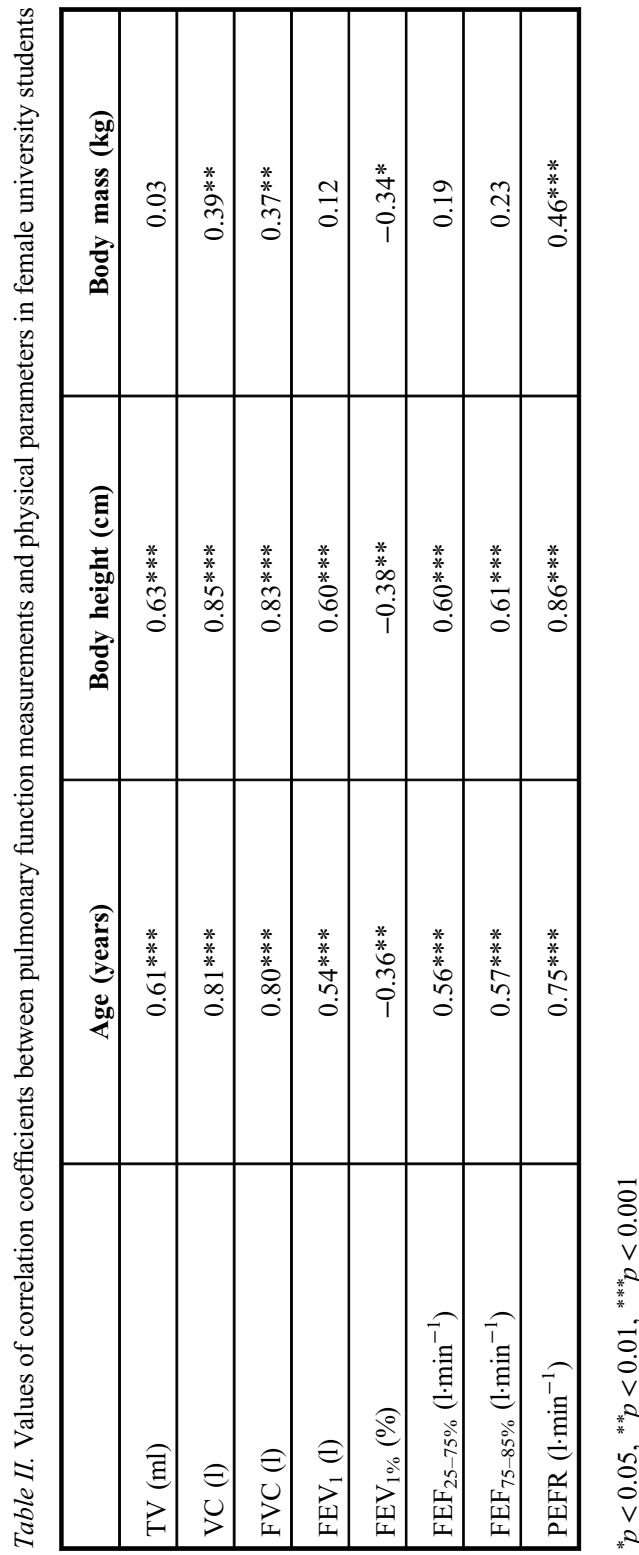


Table III. Simple regression norms for the prediction of pulmonary function measurements from age and body height in the studied population

\begin{tabular}{|c|c|c|c|c|}
\hline $\begin{array}{l}\text { Pulmonary } \\
\text { function } \\
\text { measurement }\end{array}$ & $\begin{array}{c}\text { Regression } \\
\text { equation }\end{array}$ & $R$ & $R^{2}$ & SEE \\
\hline TV (ml) & $13.88 \mathrm{~A}+198.012$ & $0.61 * *$ & 0.372 & 51.15 \\
\hline VC (1) & $0.10 \mathrm{~A}-0.027$ & $0.81 * *$ & 0.656 & 0.21 \\
\hline FVC (1) & $0.088 \mathrm{~A}+0.098$ & $0.80^{* *}$ & 0.640 & 0.19 \\
\hline $\mathrm{FEV}_{1}(1)$ & $0.048 \mathrm{~A}+0.75$ & $0.54 * *$ & 0.291 & 0.21 \\
\hline $\mathrm{FEV}_{1 \%}(\%)$ & $-1.30 \mathrm{~A}+117.91$ & $-0.36^{*}$ & 0.129 & 9.39 \\
\hline $\mathrm{FEF}_{25-75 \%}\left(1 \cdot \mathrm{min}^{-1}\right)$ & $9.62 \mathrm{~A}-11.62$ & $0.56^{* *}$ & 0.314 & 0.83 \\
\hline $\mathrm{FEF}_{75-85 \%}\left(1 \cdot \mathrm{min}^{-1}\right)$ & $6.40 \mathrm{~A}-70.05$ & $0.57 * *$ & 0.325 & 0.82 \\
\hline $\operatorname{PEFR}\left(1 \cdot \mathrm{min}^{-1}\right)$ & $8.27 \mathrm{~A}+278.48$ & $0.75^{* *}$ & 0.562 & 50.32 \\
\hline TV (ml) & $8.74 \mathrm{H}-852.80$ & $0.63 * *$ & 0.397 & 0.78 \\
\hline VC (l) & $0.065 \mathrm{H}-7.82$ & $0.85^{* *}$ & 0.722 & 0.53 \\
\hline FVC (1) & $0.056 \mathrm{H}-6.62$ & $0.83^{* *}$ & 0.689 & 0.56 \\
\hline $\mathrm{FEV}_{1}(\mathrm{l})$ & $0.033 \mathrm{H}-3.24$ & $0.60 * *$ & 0.360 & 0.80 \\
\hline $\mathrm{FEV}_{1 \%}(\%)$ & $-0.83 \mathrm{H}+218.76$ & $-0.38^{*}$ & 0.144 & 0.92 \\
\hline $\mathrm{FEF}_{25-75 \%}\left(1 \cdot \mathrm{min}^{-1}\right)$ & $6.28 \mathrm{H}-774.61$ & $0.60 * *$ & 0.360 & 0.80 \\
\hline $\mathrm{FEF}_{75-85 \%}\left(1 \cdot \mathrm{min}^{-1}\right)$ & $4.17 \mathrm{H}-576.88$ & $0.61^{* *}$ & 0.372 & 0.79 \\
\hline PEFR $\left(1 \cdot \mathrm{min}^{-1}\right)$ & $5.78 \mathrm{H}-437.11$ & $0.86^{* *}$ & 0.737 & 51.06 \\
\hline
\end{tabular}

A $=$ age, $\mathrm{H}=$ body height, $\mathrm{SEE}=$ standard error of estimate. ${ }^{*} p<0.01,{ }^{* *} p<0.001$

According to the proposal of Bandyopadhyay (2), the influence of instrumentation, standardization, and testing procedures on the studied parameters does not arise in the present context because both studies involved the same instruments and experimental protocol. The cumulative beneficial effects of physical activity and nutrition on pulmonary health were probably swayed out by the detrimental effects of increased urbanization and industrialization in the currently studied subjects who in turn exhibited significantly lower values of VC, FVC, and $\mathrm{FEV}_{1}$ than those reported by Chatterjee and Saha (8).

The present findings indicated that in spite of the uninterrupted health promotion drives by different government and non-government bodies, the respiratory health of the currently studied population did not perk up in the last 25 years. The major air pollutants that influence the pulmonary functions are sulfur dioxide $\left(\mathrm{SO}_{2}\right)$, nitrogen dioxide $\left(\mathrm{NO}_{2}\right)$, suspended particulate matters of less than $10 \mu \mathrm{m}\left(\mathrm{PM}_{10}\right)$, and ozone $\left(\mathrm{O}_{3}\right)(24)$. The rapid changes of such factors in the air are alarming in rural, urban, and peri-urban areas of India due to increased number of motor vehicles, industrial pollutants, power generation, domestic fuel use, refuse burning, and emissions from other miscellaneous sources (1). Data suggest that the $\mathrm{SO}_{2}$ level in the air has been gradually decreasing in different places of India since 2001 
Table IV. Multiple regression norms for the prediction of pulmonary function measurements in female university students

\begin{tabular}{|l|c|c|c|c|}
\hline $\begin{array}{l}\text { Pulmonary } \\
\text { function } \\
\text { measurement }\end{array}$ & $\begin{array}{c}\text { Regression } \\
\text { equation }\end{array}$ & $R$ & $R^{2}$ & SEE \\
\hline TV (ml) & $\begin{array}{c}-518.31+7.28 \mathrm{~A}+ \\
5.55 \mathrm{H}\end{array}$ & $0.67^{* *}$ & 0.449 & 0.74 \\
\hline VC (1) & $\begin{array}{c}-5.424+0.05 \mathrm{~A}+ \\
0.042 \mathrm{H}\end{array}$ & $0.89^{* *}$ & 0.792 & 0.46 \\
\hline $\mathrm{FVC}(1)$ & $\begin{array}{c}-4.583+0.047 \mathrm{~A}+ \\
0.036 \mathrm{H}\end{array}$ & $0.86^{* *}$ & 0.740 & 0.47 \\
\hline $\mathrm{FEV}_{1}(1)$ & $\begin{array}{c}-77.81+0.019 \mathrm{~A}+ \\
0.51 \mathrm{H}\end{array}$ & $0.61^{* *}$ & 0.372 & 0.80 \\
\hline $\mathrm{FEV}_{1 \%}(\%)$ & $\begin{array}{c}189.75-0.68 \mathrm{~A}- \\
0.55 \mathrm{H}\end{array}$ & $0.41^{*}$ & 0.168 & 0.91 \\
\hline $\mathrm{FEF}_{25-75 \%\left(1 \cdot \mathrm{min}^{-1}\right)}$ & $\begin{array}{c}-555.74+4.80 \mathrm{~A}+ \\
4.19 \mathrm{H}\end{array}$ & $0.63^{* *}$ & 0.397 & 0.78 \\
\hline $\mathrm{FEF}_{75-85 \%}\left(1 \cdot \mathrm{min}^{-1}\right)$ & $\begin{array}{c}-454.81+3.14 \mathrm{~A}+ \\
2.94 \mathrm{H}\end{array}$ & $0.76^{* *}$ & 0.578 & 0.65 \\
\hline${\mathrm{PEFR}\left(1 \cdot \mathrm{min}^{-1}\right)}^{-316.22+3.09 \mathrm{~A}+}$ & $0.89^{* *}$ & 0.792 & 0.46 \\
\hline
\end{tabular}

$\mathrm{A}=$ age, $\mathrm{H}=$ body height, $\mathrm{SEE}=$ standard error of estimate. ${ }^{*} p<0.01,{ }^{* *} p<0.001$

and its level reached below the recommended standard level of $50 \mu \mathrm{g} \cdot \mathrm{m}^{-3}$ in Kolkata, India (6). According to the available reports of Central Pollution Control Board (CPCB) and National Ambient Air Quality Status (NAAQS) of Ministry of Environment and Forests of Government of India, the levels of $\mathrm{NO}_{2}, \mathrm{O}_{3}$, and $\mathrm{PM}_{10}$ in the air have increased markedly during the last 15 years and the present data suggest that the level of these factors has gone far above the recommended levels of 40,100 , and $60 \mu \mathrm{g} \cdot \mathrm{m}^{-3}$, respectively (6). The changes in these environmental toxic parameters adversely affect the respiratory functions (24) and that might be responsible for the decrease in $\mathrm{VC}, \mathrm{FVC}$, and $\mathrm{FEV}_{1}$ in the population presently studied. Nevertheless, a further detailed study is needed to explore the definite cause of such variation in the parameters studied.

Rao et al. (42) reported similar values of pulmonary function measurements in their study with 60 healthy women of 15-40 years of age. They performed the study in the same population using different experimental techniques. Some other studies reported higher values of pulmonary function measurements in the same age group of females from Northern and Western provinces of India (21, 25-27).

PFTs reported in American, Jordanian, and European populations were much higher than the currently studied population $(23,31,35,44,45)$. Better socioeconomic status and nutritional habit, superior outdoor practices and enhanced growth of their thoracic cage as well as musculoskeletal system might be the cause of such higher PFTs in those overseas populations. Over and above, these countries have much better environmental conditions 
than cities in India. According to the available literature and reports of the relevant environmental agencies $(18,24,48)$, the air pollution levels in European $\left(\mathrm{SO}_{2}=125 \mu \mathrm{g} \cdot \mathrm{m}^{-3}\right.$, $\mathrm{NO}_{2}=40 \mu \mathrm{g} \cdot \mathrm{m}^{-3}, \mathrm{PM}_{10}=40 \mu \mathrm{g} \cdot \mathrm{m}^{-3}$, and $\mathrm{O}_{3}=120 \mu \mathrm{g} \cdot \mathrm{m}^{-3}$, respectively) and American cities $\left(\mathrm{SO}_{2}=84 \mu \mathrm{g} \cdot \mathrm{m}^{-3}, \mathrm{NO}_{2}=107 \mu \mathrm{g} \cdot \mathrm{m}^{-3}, \mathrm{PM}_{10}=150 \mu \mathrm{g} \cdot \mathrm{m}^{-3}\right.$, and $\mathrm{O}_{3}=287 \mu \mathrm{g} \cdot \mathrm{m}^{-3}$, respectively) were better than the Indian cities $\left(\mathrm{SO}_{2}=12 \mu \mathrm{g} \cdot \mathrm{m}^{-3}, \mathrm{NO}_{2}=70 \mu \mathrm{g} \cdot \mathrm{m}^{-3}\right.$, and $\mathrm{PM}_{10}=135 \mu \mathrm{g} \cdot \mathrm{m}^{-3}$, respectively). However, the air level of $\mathrm{NO}_{2}$ in USA showed more or less similar data in comparison to Kolkata, India. These better environmental conditions could have helped to maintain a better pulmonary health in the overseas populations. Anthropometric characteristics of westerners indicated that they were on average somewhat larger than those in Asia and the stature in turn was significantly correlated with the pulmonary function measurements (47). Therefore, well-built physique of westerners was a direct explanation for their better pulmonary function measurements compared to Indian populations.

All the pulmonary function variables had a significant correlation with age and body height except for $\mathrm{FEV}_{1 \%}$. Age showed a significant negative correlation with the PFTs except for $\mathrm{FEV}_{1 \%}$. This contradicts to earlier reports $(4,8,40,46,47)$ that reported significant negative correlation between age and pulmonary function measurements. This was probably due to smaller age range in the present investigation and corroborated with the previous studies of Bandyopadhyay et al. (3) and Bandyopadhyay (2).

On the basis of the existence of significant positive correlation between physical parameters and pulmonary function measurements, the regression equations for predicting PFTs from physical parameters in the population studied have been computed (Tables III and IV). The value of $\mathrm{FEV}_{1 \%}$ was in agreement with other previous findings in Indian and

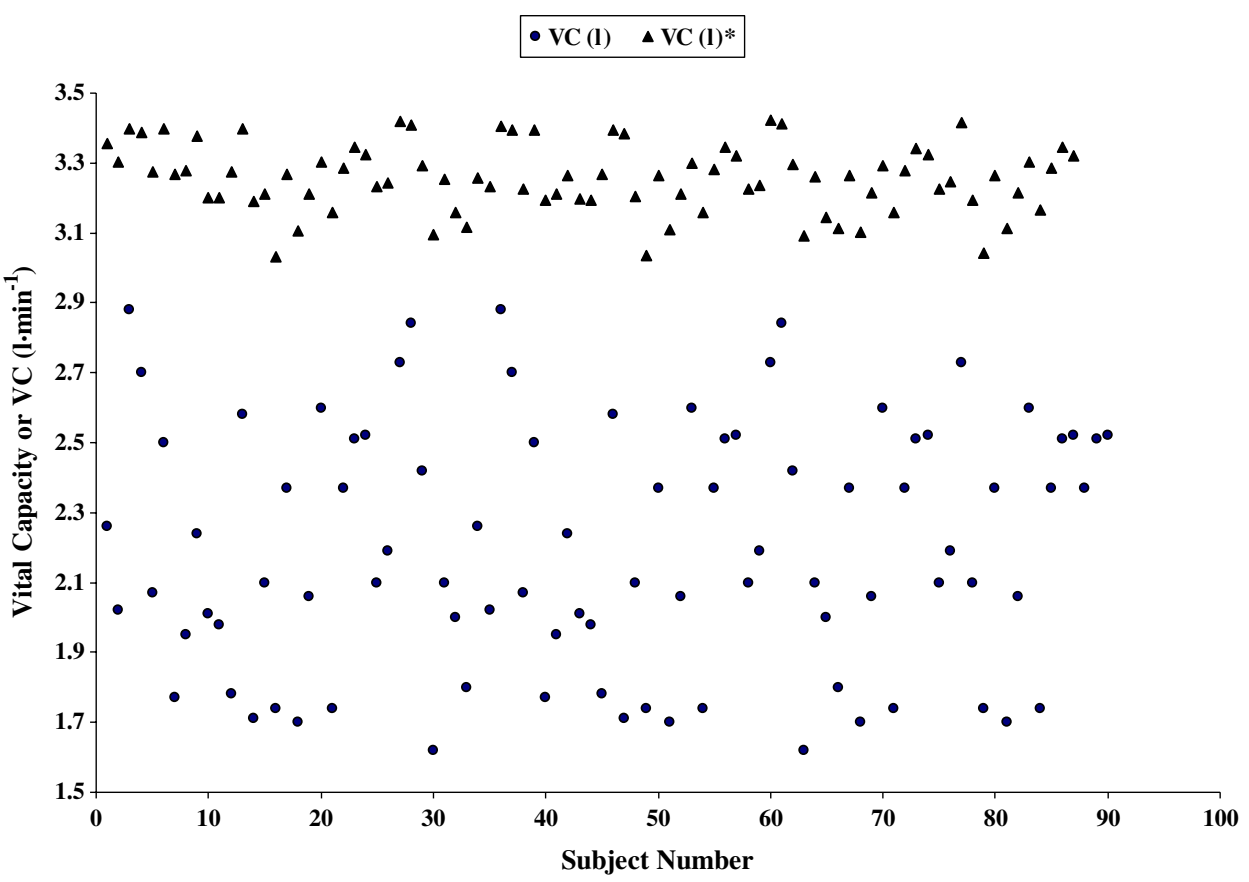

Fig. 1. Plotting of vital capacity (VC) in female university students of Kolkata - comparison with the values predicted from the standard norms prescribed in the present study and by Chatterjee and Saha $(7)^{*}$ 


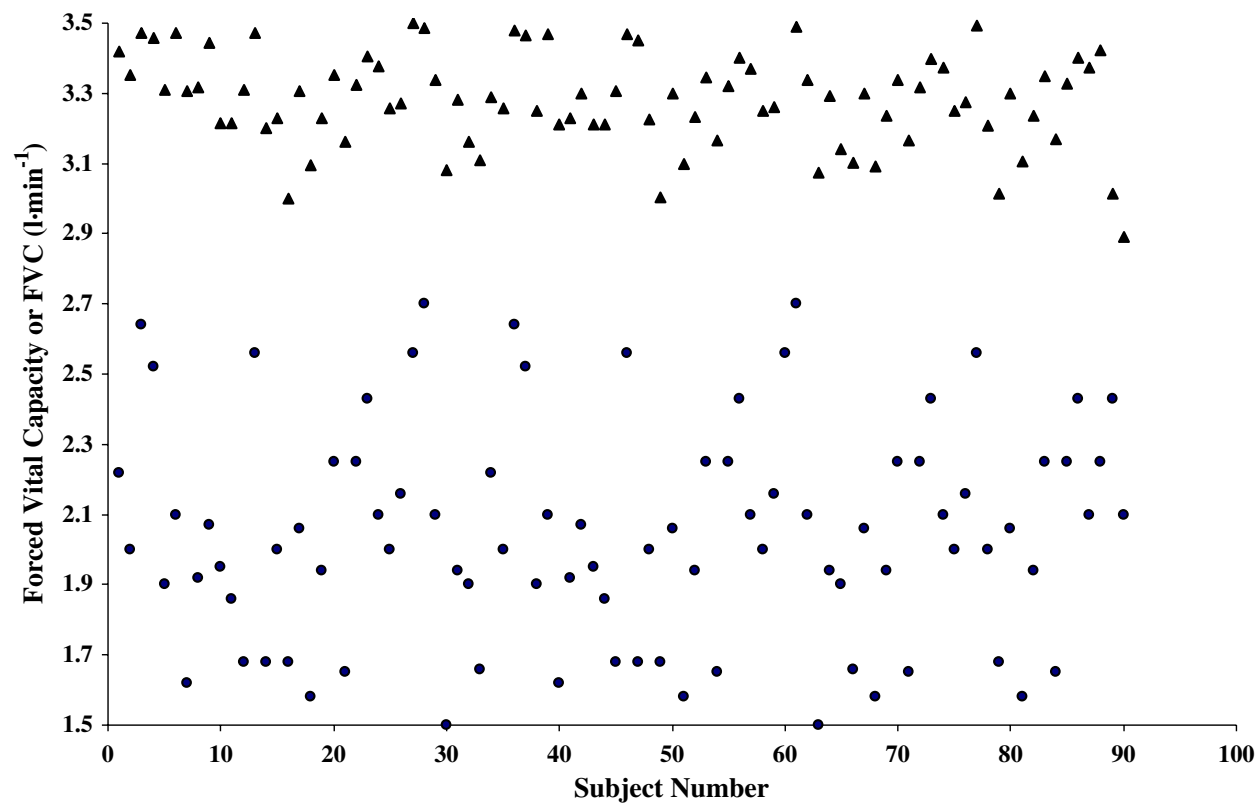

Fig. 2. Plotting of forced vital capacity (FVC) in female university students of Kolkata - comparison with the values predicted from the standard norms prescribed in the present study and by Chatterjee and Saha (7)*

$$
\bullet \operatorname{FEV}_{1}(\mathbf{l}) \triangle \operatorname{FEV}_{1}(\mathbf{l}) *
$$

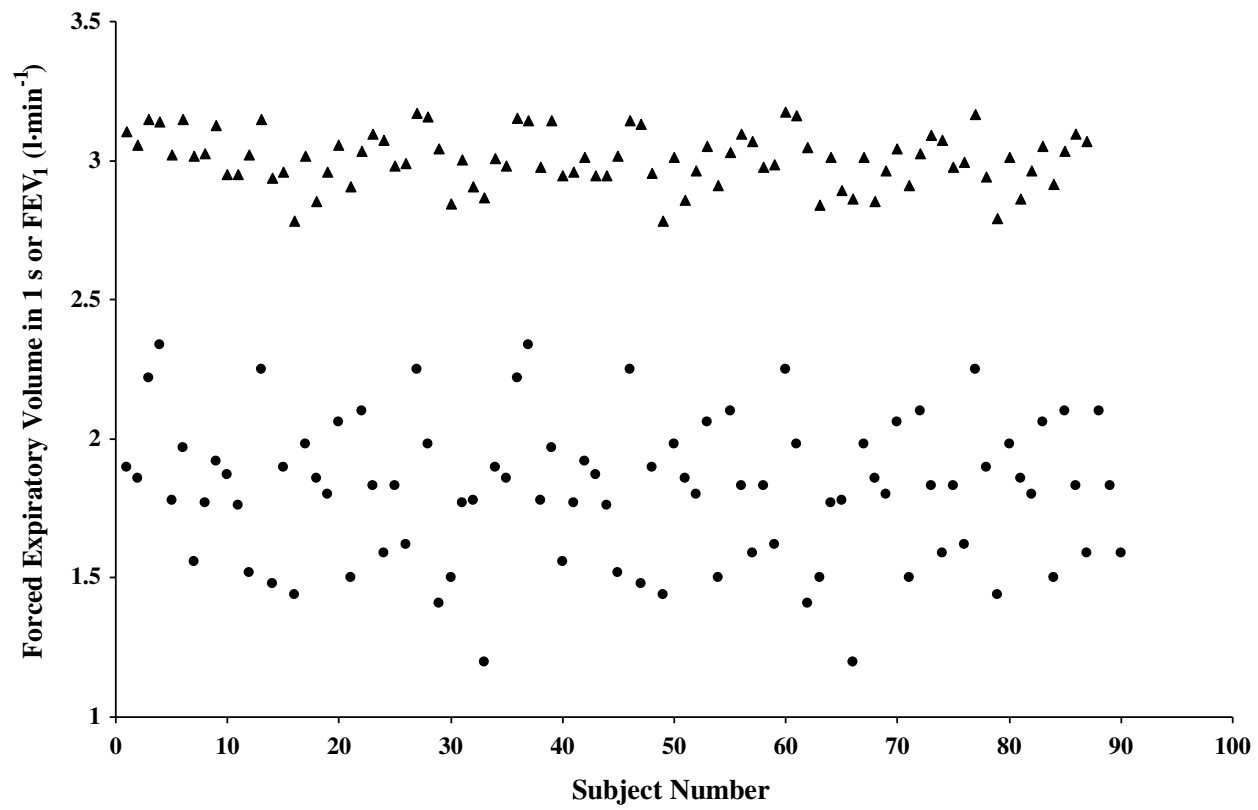

Fig. 3. Plotting of forced expiratory volume in $1 \mathrm{~s}\left(\mathrm{FEV}_{1}\right)$ in female university students of Kolkata - comparison with the values predicted from the standard norms prescribed in the present study and by Chatterjee and Saha (7)* 


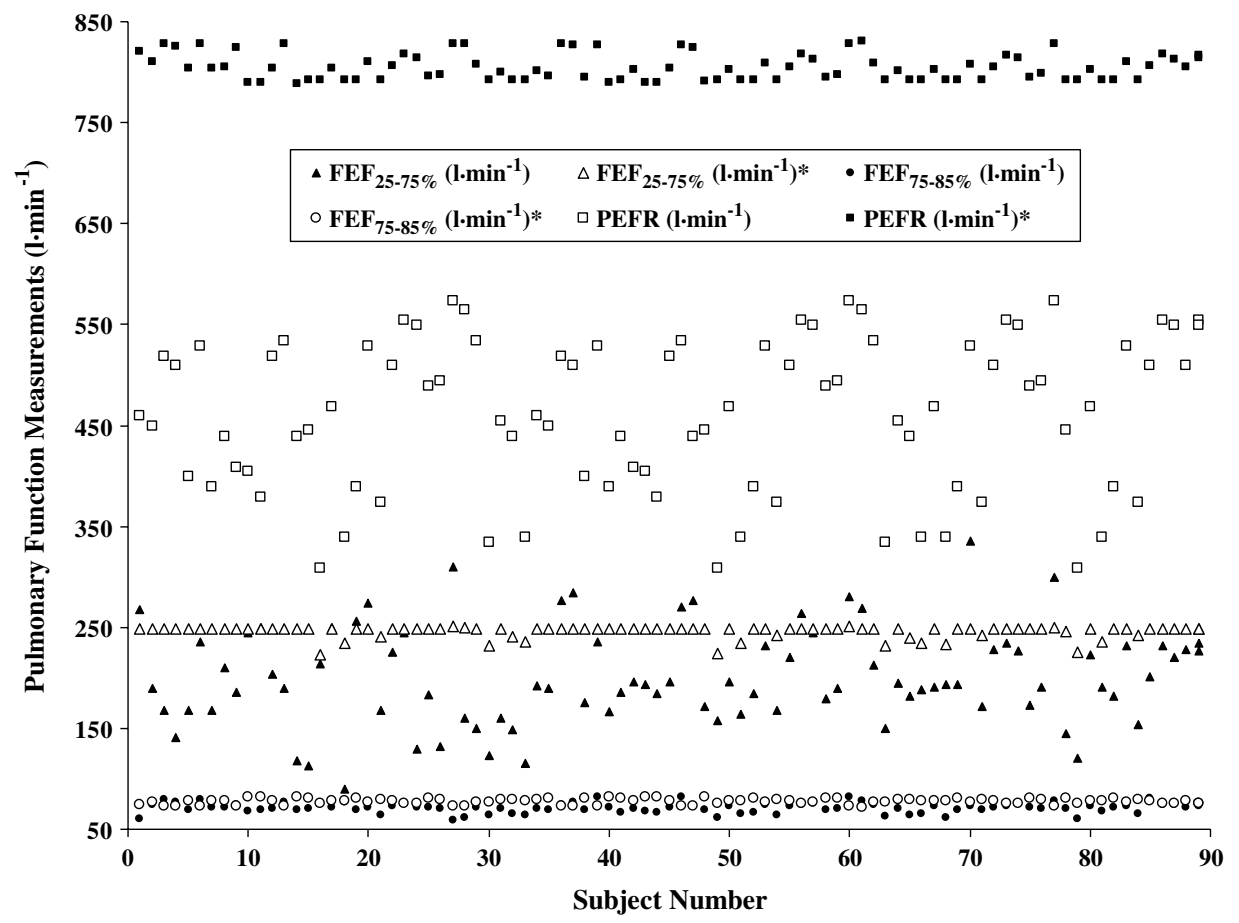

Fig. 4. Plotting of $\mathrm{FEF}_{25-75 \%}, \mathrm{FEF}_{75-85 \%}$, and PEFR in female university students of Kolkata - comparison with the values predicted from the standard norms prescribed in the present study and by Chatterjee and Saha (7)*

overseas populations and the normal range of $\mathrm{FEV}_{1 \%}$ indicated that the subjects had no obstructive pulmonary diseases. PEFR, that indicates one's pulmonary function status (4), depicted significant positive correlation with age, body height, and body mass. Along with this $\mathrm{FEF}_{25-75 \%}$ and $\mathrm{FEF}_{75-85 \%}$ also showed significant positive correlation with age and body height.

PFTs depicted significant correlation with age, body height, and body mass. However, body mass was not considered in computing the regression equations because age and body height had a more consistent relationship and higher values of correlation coefficient $(r)$ with pulmonary function variables. The standard errors of the estimate of the computed simple and multiple regression equations are small enough to recommend these equations for predicting pulmonary function measurements from age and body height in the studied population. The standard error of estimates (SEEs) of the regression norms are $50 \%$ less than those of earlier proposed norms by Chatterjee and Saha (8) and therefore the present regression norms would predict pulmonary function measurements more precisely and accurately in the studied population. These regression norms would be of practical use in epidemiological studies and clinical settings. Predicted values of the lung volumes using currently derived equations and earlier proposed equations of Chatterjee and Saha (8) have been plotted in Figs 1-4. These figures depicted a wide range of variation when the values of PFTs were predicted using the earlier norms and these findings are in agreement about the conception that the earlier equations cannot be applied in the present context anymore. 


\section{Conclusion}

The study indicated that the PFTs of female university students of Kolkata were within the normal range. The expiratory flow rates did not vary with the values reported 20 years back, but the absolute values of the lung volumes were significantly reduced compared to the values reported in the earlier study. Rest of the parameters did not demonstrate any significant transformation between the two studies. The SEE of the presently computed norms was substantially smaller than those reported by Chatterjee and Saha (8); therefore, the currently derived equations are considered to be more appropriate and suitable for a precise and accurate prediction of PFTs in the population studied.

\section{Acknowledgement}

The authors would like to thank the University of Calcutta for their financial assistance through Contingency under Grant BI92(7).

\section{REFERENCES}

1. Agrawal M: Effect of air pollution on agriculture: an issue of national concern. Natl. Acad. Sci. Lett. 28, 93-106 (2005)

2. Bandyopadhyay A: Pulmonary function studies in young healthy Malaysians of Kelantan, Malaysia. Indian J. Med. Res. 134, 653-657 (2011)

3. Bandyopadhyay A, Basak AK, Tripathy S, Bandyopadhyay P: Peak expiratory flow rate in female brick field workers of West Bengal, India. Ergonomics SA 18, 22-27 (2006)

4. Bandyopadhyay A, Bhattacharjee I, Dalui R, Pal S: Pulmonary function studies of healthy non-smoking male university students of Kolkata, India - revisited. Malays. J. Med. Sci. 20, 17-24 (2013)

5. Bergland E, Birath G, Bjure J: Spirometric studies in normal subjects. Forced expirograph in subjects 7 and 70 years of age. Acta Med. Scand. 173, 185-192 (1963)

6. Central Pollution Control Board (2012): National Ambient Air Quality Status and Trends in India - 2010. Ministry of Environment \& Forests, New Delhi

7. Chatterjee S, Mandal A: Pulmonary function studies in healthy school boys of West Bengal. Jpn. J. Physiol. 41, 797-808 (1991)

8. Chatterjee S, Saha D: Pulmonary function studies in healthy non-smoking women of Calcutta. Ann. Hum. Biol. 20, 31-38 (1993)

9. Cherniack RM, Raber MB: Normal standards for ventilatory functions using automated wedge spirometer. Am. Rev. Respir. Dis. 106, 38-46 (1972)

10. Chuan PS, Chia M: Respiratory function tests in normal adult Chinese in Singapore. Singapore Med. J. 10, 265-271 (1969)

11. Cotes JE, Malhotra MS: Differences in lung functions between Indians and Europeans. J. Physiol. 77, 17-18 (1964)

12. Cotes JE, Rossiter CE, Higgins ITT, Gilson JC: Average normal values for the forced expiratory volume in white Caucasian males. Br. Med. J. 23, 1016-1019 (1966)

13. Da Costa JL: Pulmonary function studies in healthy Chinese adults in Singapore. Am. Rev. Respir. Dis. 104, 128-131 (1971)

14. Dockery DW, Ware JH, Ferris BG: Distribution of forced expiratory volume in one second and forced vital capacity in healthy, white, adult never-smokers in six US cities. Am. Rev. Respir. Dis. 13, 511-520 (1985)

15. DuBois D, DuBois EF: Clinical calorimetry: a formula to estimate approximate surface area if height and weight be known. Arch. Intern. Med. 17, 863-871 (1916)

16. Dufétel P, Pigearias B, Lonsdorfer J, Derossi DC, Faltot PJ: Spirometric reference values in Senegalese black adults. Eur. Respir. J. 2, 352-358 (1989)

17. Dupont WD, Plummer WD Jr: Power and sample size calculation for studies involving linear regression. Control. Clin. Trials 19, 589-601 (1998)

18. European Environment Agency (2012): Air Quality in Europe - 2012 Report. European Environment Agency, Copenhagen 
19. Ferris BG: Epidemiology standardization project (American Thoracic Society). Am. Rev. Respir. Dis. 118, $1-120$ (1978)

20. Gregg I, Nunn AJ: Peak expiratory flow rate in normal subjects. Br. Med. J. 3, 282-284 (1973)

21. Gupta P, Gupta S, Ajmera RL: Lung function tests in Rajasthani subjects. Indian J. Physiol. Pharmacol. 23, 8-14 (1979)

22. Hetzel MR: The pulmonary clock. Thorax 36, 481-486 (1981)

23. Higgins MW, Keller JB: Seven measures of ventilatory lung function. Population values and their comparison of their ability to discriminate between persons with and without chronic respiratory symptoms and disease, Tecumsch, Michigan. Am. Rev. Respir. Dis. 108, 258-272 (1973)

24. Jain R, Palwal K (2015): Air Pollution and Health - Discussion Paper. The Energy and Resources Institute, New Delhi, pp. 1-21

25. Jain SK, Gupta CK: Lung function studies in healthy men and women over forty. Indian J. Med. Res. 55, 612-619 (1967)

26. Jain SK, Ramiah TJ: Spirometric studies in healthy women 15-40 years age. Indian J. Chest Dis. 9, 1-12 (1967)

27. Jain SK, Ramiah TJ: Normal standards of pulmonary function tests for healthy Indian men 15-40 years old: comparison of different regression equations (prediction formulae). Indian J. Med. Res. 57, 1453-1466 (1969)

28. Johannsen ZM, Erasmus LD: Clinical spirometry in normal Bantu. Am. Rev. Respir. Dis. 97, $985-997$ (1968)

29. Jones AY, Dean E, Lam PK, Lo SK: Discordance between lung function of Chinese university students and 20-year-old established norms. Chest 128, 1297-1303 (2005)

30. Kory RC, Challahan R, Boren HG, Syner JC: The veterans administration-army cooperative study of pulmonary function: I. Clinical spirometry in normal men. Am. J. Med. 30, 243-258 (1961)

31. Lawther PJ, Brook AGF, Waller RE: Respiratory function measurements in a cohort of medical students, a ten year follow-up. Thorax 33, 773-778 (2011)

32. Malik SK, Jindal SK: Pulmonary function tests in healthy children. Indian Pediatr. 22, 677-681 (1985)

33. Mandal A: Peak expiratory flow rates of school going girls from West Bengal. Ind. Biol. 34, 41-45 (2002)

34. Marek W, Marek EM, Muckenhoff K, Smith JH, Degens P, Kalhoff H, Kotschy LN, Kohlhäufl M: Lung function in young adults: which references should be taken? Al Ameen J. Med. Sci. 3, 272-283 (2010)

35. Morris JF, Koski A, Johnson LC: Spirometric standard for healthy non-smoking adults. Am. Rev. Respir. Dis. 103, 57-67 (1971)

36. Omar AH, Henry RL: Peak expiratory flow rate of Malaysian children. Med. J. Malaysia 46, $82-87$ (1991)

37. Omar BH, Henry RL: Ethnic differences in normal spirometric lung function of Malaysian children. Respir. Med. 88, 349-356 (1994)

38. Oxhj H, Jeppesen GM, Larson VH, Jorgensen B: Spirometry in healthy adult never-smokers. Clin. Physiol. 8, 329-339 (1988)

39. Pande JN, Verma SK, Singh SPN, Guleria R, Khilnani GC: Respiratory pressures in normal Indian subjects. Ind. J. Chest Dis. Allied Sci. 40, 251-256 (1998)

40. Paoletti P, Pistelli G, Fazzi P: Reference values for vital capacity and flow volume curves from a general population study. Bull. Eur. Physiopathol. Respir. 22, 451-459 (1986)

41. Quanjer PH: Standardized lung function testing. Report working party. Bull. Eur. Physiopathol. Respir. 5, $1-95$ (1983)

42. Rao MN, Gupta AS, Saha PN, Devi SA: Physiological norms in Indians: pulmonary capacities in health. Indian J. Med. Res. 38, 1-104 (1961)

43. Roca J, Sanchis J, Augusti-Vidal A: Spirometric reference values from a Mediterranean population. Bull. Eur. Physiopathol. Resp. 22, 217-224 (1986)

44. Schmidt CD, Dickman ML, Gardner RM, Brough FK: Spirometric standard for healthy elderly men and women. Am. Rev. Respir. Dis. 108, 933-939 (1973)

45. Silman NA, Dajani BM, Dajani HM: Ventilatory function test values of healthy adult Jordanians. Thorax 36 , 546-549 (1981)

46. Singh R, Singh HJ, Sirisinghe RG: Forced vital capacity in Malaysian females. Jpn. J. Physiol. 42, 407-414 (1992)

47. Singh R, Singh HJ, Sirisinghe RG: Spirometric volumes in Malaysia males. Southeast Asian J. Trop. Med. Public Health 25, 341-348 (1994)

48. US Environmental Protection Agency Progress Report, 2012.

49. Virani N, Shah B, Celly A: Pulmonary function studies in healthy non-smoking adults in Sri Aurobindo Ashram, Pondicherry. Indian J. Med. Res. 114, 177-184 (2001)

50. Wu M-C, Yang S-P: Pulmonary function studies in healthy Chinese. J. Formosan Med. Assoc. 61, 110-131 (1962) 